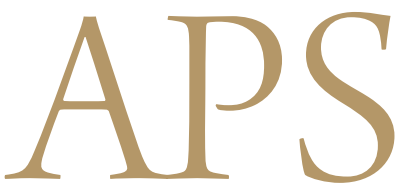

Archives of Plastic Surgery

\title{
Design of a combined cartilage graft crusher, morselizer and holder for use in rhinoplasty
}

\author{
Jonas Röjdmark, Mubashir Cheema \\ Department of Plastic Surgery, Akademikliniken Clinic, Stockholm, Sweden
}

\begin{abstract}
A combined cartilage holder and crusher is described that allows the surgeon to hold, crush, morselize, and suture a single piece or stack of cartilage graft without letting it slip. The customized slit-shaped jaws allow adequate room for the suture needle, while the serrated surfaces hold the cartilage firmly. The use of this instrument is advocated primarily in rhinoplasty for manipulating and suturing a small cartilage graft or a stack of grafts. The use of this instrument may be extended to aesthetic or reconstructive cases where cartilage grafts need to be sutured or shaped, as in eyelid, ear, and nipple reconstruction.
\end{abstract}

Keywords Rhinoplasty / Cartilage graft / Shield graft

\author{
Correspondence: Jonas Röjdmark \\ Department of Plastic Surgery, \\ Akademikliniken Clinic, Storängsvägen \\ 10, Stockholm 11542, Sweden \\ Tel: $+46-736420884$ \\ Fax: $+46-86145420$ \\ E-mail: jonas.rojdmark@ak.se
}

\section{INTRODUCTION}

The goal of modern rhinoplasty is to achieve an aesthetically pleasant and natural-appearing nose, while ensuring good longterm postoperative results with a preservation of normal function [1-3]. A successful operation depends on a detailed evaluation, an accurate identification of the patient's problem, meticulous individualized planning, and proper execution of the surgical steps [1,3-5]. In addition to the surgeon's knowledge, skill, and experience, the use of appropriate instruments is a prerequisite for performing a reliable operation. This makes surgical instruments essential for achieving consistent results. Even small discrepancies in equipment may result in a noticeable difference between the planning and execution of a procedure, potentially affecting the outcome. In this study we present a new instrument, which in our opinion facilitates the surgical procedure and makes it more straightforward to obtain desirable results.

\section{IDEA}

The instrument is custom-made by Scatter Instruments, Sialkot, Pakistan, and is similar in size $(200 \mathrm{~mm} \times 95 \mathrm{~mm})$ to a bone nibbler. It has two elongated flattened jaws whose serrated surfaces precisely meet each other (Figs. 1-3). Each jaw (28 mm $\times$ $16 \mathrm{~mm}$ ) has a $2 \mathrm{~mm} \times 15 \mathrm{~mm}$ longitudinal slit in its middle that extends nearly two-thirds of the length of the jaw (Figs. 1-3). The jaws taper towards their distal end. The instrument is designed with a double-action hinge to allow for strong pressure to be applied and is similar in height and weight to a bone nibbler, familiar to most surgeons. The serrated flattened jaws provide a firm hold on either side to allow the graft to be cut to the desired shape and size. In order to suture, the graft is held so that the point to be sutured is positioned in the slit. The slit is wide enough to allow the curve of a suture needle to pass through with ease. It is also long enough to accommodate varying lengths of cartilage graft. If needed, the flattened jaws can also be used to crush the graft as well. 


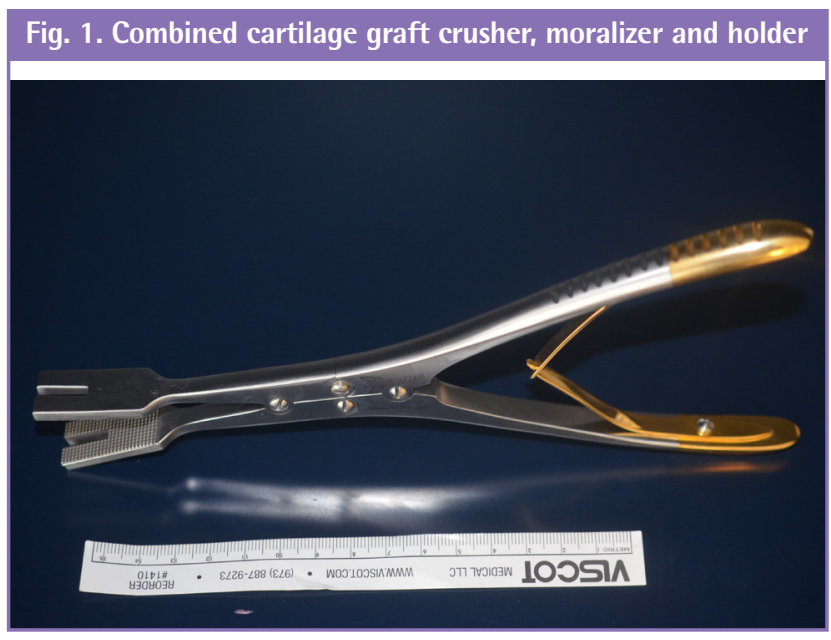

Fig. 2. "Close-up" of the instruments jaws

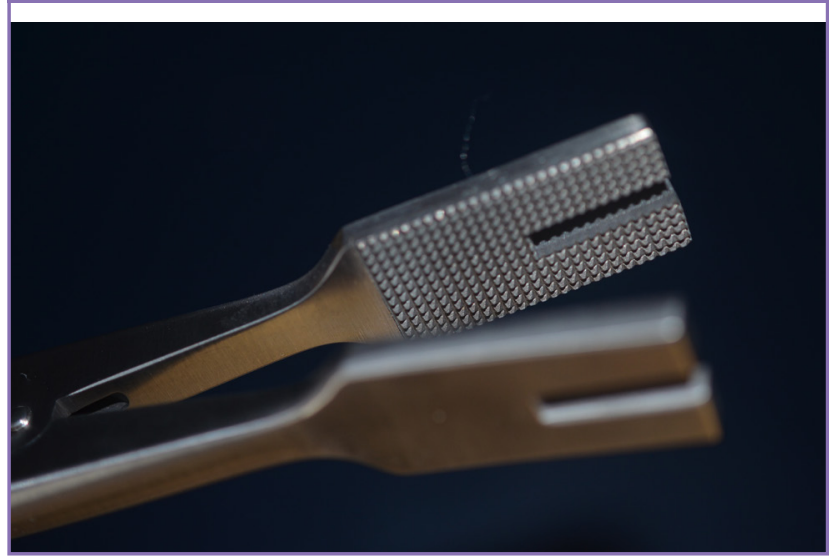

\section{DISCUSSION}

Cartilage grafts are commonly sourced from nasal septal, conchal, or rib cartilage $[6,7]$. Due to its unique cellular structure, low metabolism, and nutrition by diffusion [8,9], cartilage can be stacked in layers. A cartilage graft may be used as a strut, as a layered graft, or as a filler in primary or secondary rhinoplasty. The graft may additionally be morselized and/or crushed to achieve the desired configuration. Importantly, an increase in graft thickness can only be achieved by stacking layers of thin cartilage, or by carving a block of rib cartilage.

The current method of handling cartilage grafts is with forceps to perform layer-by-layer suturing. Morselizers are used to make these grafts more supple in order to enhance the nasal form without creating visible deformities.

In many instances, however, handling multiple cartilage pieces with forceps and simple morselizers in a layer-by-layer manner can be very difficult. The cartilage pieces tend to slip, and the suture holding the morselized pieces does so in an imprecise manner. Suturing together pieces of cartilage becomes increas-

\section{Fig. 3. Instrument during surgical activity}

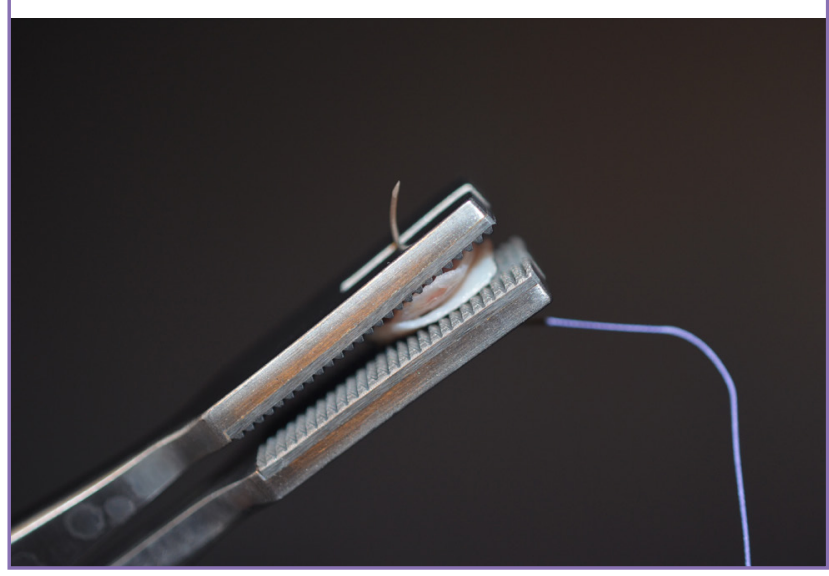

ingly difficult with smaller and thinner graft material and when multiple layers of cartilage are involved. The use of toothed forceps tends to break the graft, and even Adson Brown cartilage forceps do not always allow delicate manipulation. Passing a fine suture (5/0 or $6 / 0$ monofilament) through the cartilage can therefore be difficult and frustrating for the surgeon. In the presence of thin pieces of graft, there is a risk of imprecise suture placement or breakage of the graft while manipulating it. Ideally, the cartilage needs to be held in two places with precision and an appropriate amount to force to hold it steady for manipulation and suture placement. The senior author (JR) has an annual practice of over 300 rhinoplasties and frequently encounters these problems. The instrument presented in this paper was therefore designed to address the perceived shortcomings of existing instruments in manipulating and working on cartilage grafts.

The senior author has been using this instrument for many months now, and it has replaced a traditional (often smaller and less controllable) morselizer and forceps for handling cartilage grafts. We believe this would be a very welcome instrument in the hands of any rhinoplasty surgeon for handling graft material for simple primary rhinoplasties, as well as complicated secondary cases. Since the instrument can work with any cartilage graft, its use may not be limited to rhinoplasty. Cartilage grafts are used in reconstructive surgery (e.g., eyelid and auricular reconstruction) as well as aesthetic surgery (e.g., nipple reconstruction). The instrument described herein may therefore be used for cartilage manipulation in those situations as well.

The use of high quality instruments is fundamental for controlled manipulation of tissues, minimizing surgical trauma, decreasing the duration of the operative procedure and, ultimately, ensuring consistent postoperative results. The instrument described and developed herein has helped make rhinoplasty procedures easier in our practice. This new instrument makes it 
possible to accurately suture the pieces of cartilage together by holding them firmly to prevent any slippage of the individual cartilage pieces, thereby saving time and avoiding unnecessary frustration. It also doubles as an instrument for morselizing cartilage, avoiding the need for a separate instrument for that purpose. No similar instrument with these unique features has, to our knowledge, been described in the literature. The only drawback for other surgeons may be that this instrument is not yet produced by major suppliers and they have to source it from the manufacturer directly. It has become an essential part of the surgical armamentarium of the first author.

\section{NOTES}

\section{Conflict of interest}

No potential conflict of interest relevant to this article was reported.

\section{Author contribution}

Conceptualisation: Röjdmark J. Data curation and formal analysis: Röjdmark J. Funding: Röjdmark J. Methodology, administration and visualization: Röjdmark J. Writing original draft: Röjdmark J, Cheema M. Writing rewiew and editing: Röjdmark J. Approval: Röjdmark J, Cheema M.

\section{ORCID}

Jonas Röjdmark https://orcid.org/0000-0001-6864-8186

\section{REFERENCES}

1. Perkins SW. The evolution of the combined use of endonasal and external columellar approaches to rhinoplasty. Facial Plast Surg Clin North Am 2004; 12:35-50.

2. Daniel RK. Rhinoplasty: the first 100. In: Daniel RK, editor. Rhinoplasty. 1st ed. Boston: Little Brown; 1993. p.321-80.

3. Constantian MB. Constantian's approach. In: Gunter JP, Rohrich RJ, Adams WP Jr, editors. Dallas rhinoplasty: nasal surgery by the masters. 2nd ed. St. Louis: Quality Medical; 2007. p.1465-502.

4. Simons RL, Grunebaum LD. The endonasal approach to rhinoplasty. In: Stucker FJ, de Souza C, Kenyon GS, et al., editors. Rhinology and facial plastic surgery. 1st ed. Berlin: Springer-Verlag; 2009. p.713-21.

5. Cafferty A, Becker DG. Open and closed rhinoplasty. Clin Plast Surg 2016;43:17-27.

6. Tebbetts JB. Open and closed rhinoplasty (minus the "versus"): analyzing processes. Aesthet Surg J 2006;26:456-9.

7. Sheen JH. Closed versus open rhinoplasty--and the debate goes on. Plast Reconstr Surg 1997;99:859-62.

8. Chandawarkar RY, Cervino AL, Wells MD. Reconstruction of nasal defects using modified composite grafts. Br J Plast Surg 2003;56:26-32.

9. Silva BS, Dolci JE. Experimental study of the use of auricular cartilage with and without Gelfoam ${ }^{\circledR}$ on the nasal dorsum of rabbits. Braz J Otorhinolaryngol 2014;80:111-9. 